\title{
RELATION OF SERUM LEVEL OF S100B WITH VITILIGO ACTIVITY AND SEVERITY.
}

Abdelraheem TA (1), Mohammed BH (2), El-Sayed HS (3)and Mohammed ZM(4).

(1) professor of Dermatology, STDs and andrology department, Faculty of Medicine Fayoum University.

(2) lecturer of Dermatology, andrology and STDs, Faculty of Medicine Fayoum University.

(3) lecturer of biochemistry, Faculty of Medicine Fayoum university.

(4) Department of Dermatology, Faculty of Medicine Fayoum University.

Corresponding author: prof .Talal A. Abd-ElRaheem

E-mail address: talasam@yahoo.com

Tel:01006600360

Fax: +2 084636583

\section{Abstract}

Vitiligo is the commonest dyspigmentation disorder of skin and/or mucosa, with clinical manifestations of porcelain white patches. It is considered to be a multifactorial disease caused by the destruction of melanocytes. The aim of this study is to estimate serum S100B level and to evaluate its correlation with vitiligo activity and severity. Sixty three patients had vitiligo and twenty healthy volunteers as control group were included in our study. All cases were assessed for severity by VASI score and the disease activity for the last one year. Serum S100B level was estimated in both patient and control groups. There was a highly statistically significant difference with $\mathrm{p}$-value $<0.001$ between serum S100B level and vitiligo severity measured by VASI. There was a statistically significant difference with $\mathrm{p}$-value $<0.05$ between serum
S100B level and vitiligo activity . In Conclusion, Serum S100B level could be used as a biochemical marker for vitiligo activity and severity.

Keywords : Vitiligo, Serum S100B .

\section{Introduction}

Vitiligo is the most common pigmentary disorder of skin and/or mucosa affecting 1-2\% of the world's population with clinical manifestations of porcelain white patches (1).

Vitiligo is classified broadly into nonsegmental (NSV) and segmental (SV) vitiligo. Several subphenotypes of NSV have been described, including mucosal, acrofacial, generalized, and universal (2).

Vitiligo is the result of complex interactions of biochemical, environmental and immunological events, while the precise mechanism of vitiligo pathogenesis has 
remained elusive. Many other factors have been implicated such as infections, oxidative stress, neural abnormalities, melatonin receptor alterations, and genetic susceptibility (3).

Vitiligo is essentially a clinical diagnosis. Under wood's light, it shows characteristic skin hypochromic or depigmented islands with sharp demarcations. Dermoscopy may aid in noninvasive confirmation of diagnosis (as vitiligo lesion shows reduced, absent or altered pigment network) and help excluding other clinically simulating hypopigmentary conditions (4).

$\mathrm{S} 100 \mathrm{~B}$ is a member of the family of $\mathrm{S} 100$ proteins. S100B is a damage associated molecular pattern protein expressed in melanocytes that has been proposed as a marker of melanocyte cytotoxicity and it is well established in melanoma. (5).

\section{Subjects and Methods}

The aim of this study is to estimate serum S100B level and to evaluate its correlation with vitiligo activity and severity. Sixty three patients had vitiligo and twenty healthy volunteers as control group were included in our study. All cases were assessed for severity by VASI score and the disease activity for the last one year. Serum S100B level was estimated in both patient and control groups.

\section{Results}

1-This study revealed that there was a statistically significant difference between S100B level in cases and control groups with p-value $<0.05$. 


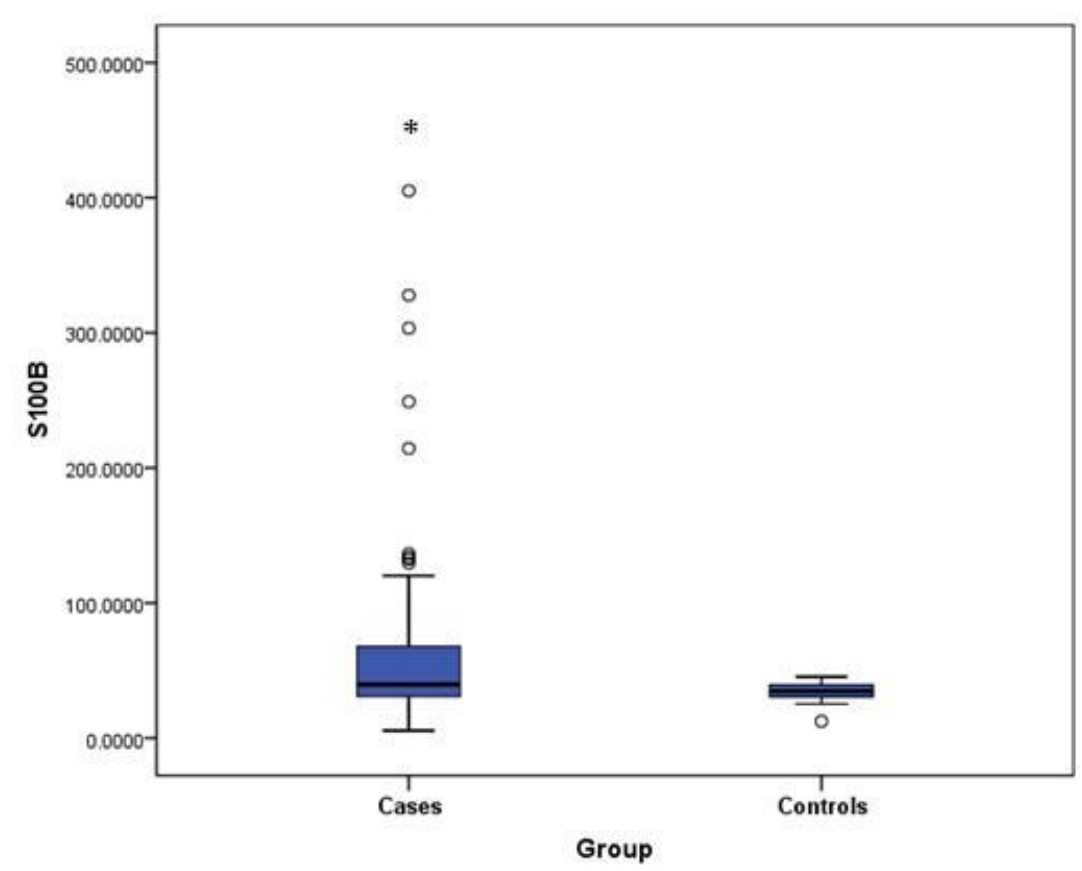

\begin{tabular}{|c|c|c|c|}
\hline \multirow{3}{*}{\begin{tabular}{|l} 
\\
S100B \\
\end{tabular}} & $\begin{array}{l}\text { Cases } \\
(\mathrm{N}=63)\end{array}$ & $\begin{array}{l}\text { Controls } \\
(\mathrm{N}=20)\end{array}$ & \multirow[t]{2}{*}{ p-value } \\
\hline & \multicolumn{2}{|c|}{$\begin{array}{c}\text { Mean } \pm \text { SD } \\
(\text { Range })\end{array}$} & \\
\hline & $\begin{array}{l}68.93 \pm 77.05 \\
(5.52-405.17)\end{array}$ & $\begin{array}{l}34.06 \pm 7.27 \\
(12.48-45.37)\end{array}$ & $\begin{array}{c}0.048 \\
\text { (Significant) }\end{array}$ \\
\hline
\end{tabular}

2- The study showed highly statistically significant correlation $(\mathrm{p}<0.001)$ between the level of S100B protein in serum of cases with disease severity measured by VASI. 


\begin{tabular}{|l|c|c|}
\hline \multirow{2}{*}{} & \multicolumn{2}{|c|}{ S100B } \\
\cline { 2 - 3 } & $\mathrm{R}$ & $\mathrm{p}$-value \\
\hline VASI score & 0.434 & $\begin{array}{c}<0.0001 \\
\text { (Highly significant) }\end{array}$ \\
\hline
\end{tabular}

3- The study showed statistically significant correlation $(\mathrm{p}<0.05)$ between the level of S100B protein in serum of cases and disease activity.

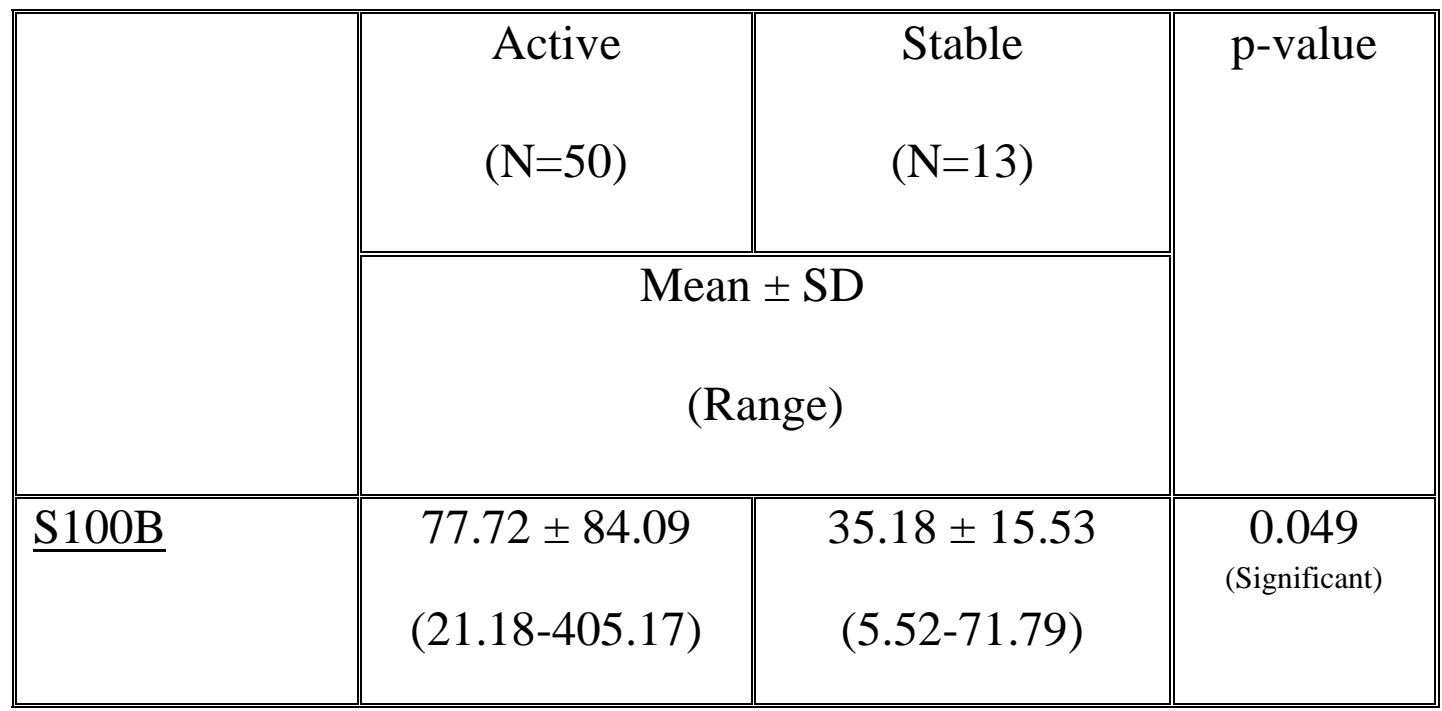




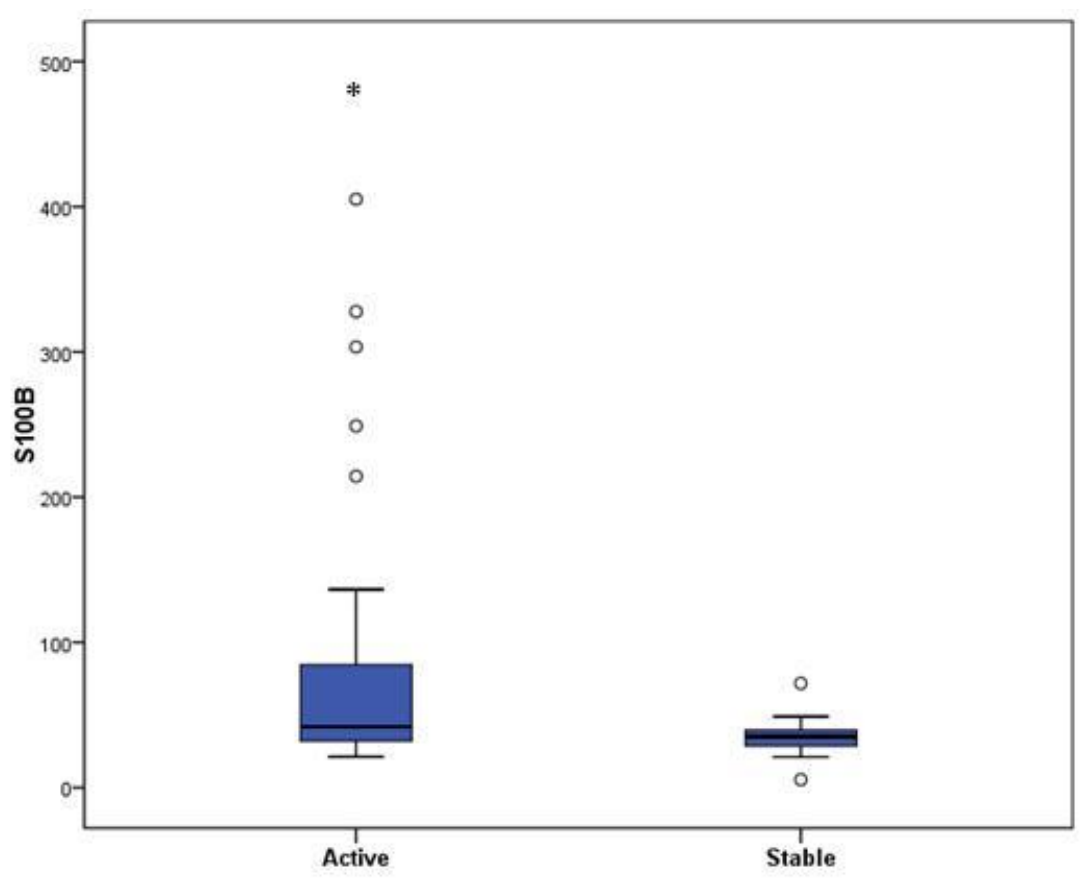

\section{Discussion}

Vitiligo is an acquired pigmentation disorder of skin and/or mucosa, with clinical manifestations of porcelain white well-defined circumscribed macules or patches. It is considered to be a multifactorial and polygenic disease caused by the destruction of melanocytes (6). Mechanism of vitiligo pathogenesis is believed to be an interplay between several factors including autoantigens and a trigger. Certain triggers, such as oxidative stress or physical trauma, expose to antigens, lead to an autoimmune response (7). Vitiligo is classified broadly into nonsegmental (NSV), which accounts for $85-90 \%$ of all cases, manifests with multifocal symmetrically distributed lesions. Several subphenotypes of NSV have been described including mucosal, acrofacial, generalized, and universal (8).
The Vitiligo Area Scoring Index (VASI) is a standardized, sensitive method to measure the product of each body region extent of de/repigmentation and percentage in hands units (set at $1 \%$ per unit) (9). $\mathrm{S} 100 \mathrm{~B}$ is a member of calcium-binding protein superfamily, considered as a damageassociated molecular pattern protein (DAMP) exerting several immunological activities. It binds to receptor for advanced glycation end products (RAGE), which induces a proinflammatory signaling cascade (10). $\mathrm{S} 100 \mathrm{~B}$ as a disease activity marker has been widely studied in melanoma indicating melanocyte cytotoxicity (11).

In our study, there was a statistically significant difference between S100B level in case group and control group with (p-value $=0.048$ ). The mean serum S100B for patients was $68.93 \pm 77.05$, and for control group was $34.06 \pm 7.27$. There was also a highly 
statistically significant correlation between S100B protein level and VASI with p- value < 0.0001. This was in agreement with Speeckaert R et al., in 2017 who studied S100B serum levels in 87 nonsegmental active vitiligo patients and found that it was positively correlated with an increased affected body surface area (BSA) with $p=$ 0.003 .

In our study, there was a statistically significant correlation between S100B protein level and disease activity with p-value $<0.05$ between active and stable patients. Also this was in consistent with Speeckaert et al. in 2017 who found higher circulating levels of S100B in patients undergoing active depigmentation in the last 6 months $(\mathrm{n}$ active $=$ $37 / 85[43.5 \%]$ vs. $n$ stable $=48 / 85[56.5 \%]$, respectively; $p=0.005)$, and even showed a marked increase in S100B serum levels in vitiligo patients with highly active vitiligo compared with patients with lower activity statuses $(n=7 / 89$ [7.9\%] vs. $n=82 / 89$ [92.1\%], respectively; $p=0.008)$.

\section{Conclusion:}

1-S100B could be a potential biomarker for vitiligo activity and severity.

2-Further studies are needed to explore more role of S100B in vitiligo pathogenesis and possible application in treatment stratigies.

\section{References}

- $\{1\}$ Sheth VM , Gunasekera NS,
Silwal S and Qureshi AA (2015):

Development and pilot testing of a vitiligo screening tool. Arch. Dermatol. Res; 307: 31-8.

- $\{2\}$ Ezzedine K, Eleftheriadou V, Whitton $M$ and van Geel N (2015): Vitiligo. Lancet; 386 (9988): 74-84.

- $\{3\}$ Rezk AF, Kemp DM, El-Domyati $\underline{\mathrm{M}}, \underline{\text { El-Din } \quad \text { WH, Lee }} \underline{\text { JB }}, \underline{\text { Uitto }}$ J, Igoucheva O and $\underline{\text { Alexeev V }}$ (2017) : Misbalanced CXCL12 and CCL5 Chemotactic Signals in Vitiligo Onset and Progression. J Invest Dermatol ;137(5):1126-34.

- $\{4\}$ Lommerts JE, Teulings H-E, Ezzedine K, van Geel N, Hartmann $A$ and Speeckaert $R$ (2016): Melanoma-associated leukoderma and vitiligo cannot be differentiated based on blinded assessment by experts in the field. J Am Acad Dermatol ; 75:1198204.

- $\{5\}$ Gilston BA, Skaar EP and Chazin WJ (2016): Binding of transition metals to S100 proteins. Sci China Life Sci ;59:792-801

- $\{6\}$ Alikhan A, Felsten LM, Daly M and Petronic-Rosic V (2011) :Vitiligo: a comprehensive overview Part I. Introduction, epidemiology, quality of life, diagnosis, differential diagnosis, associations, histopathology, etiology, and work-up. J Am.Acad.Dermatol; 65(3) 473-91. 
- $\quad\{7\}$ Tarlé RG, Nascimento LM, Mira MT, and Castro CCS (2014): Vitiligo Part 1. Anais Brasileiros de Dermatologia; 89( 3) 461-70.

- $\quad\{8\}$ Birlea SA, Spritz RA and Norris DA (2012): Vitiligo. Fitzpatrick's dermatology in general medicine; 8th ed. :792-5.

- $\quad$ 9\} Benzekri L, Ezzedine $K$ and Gauthier Y (2013): Vitiligo Potential Repigmentation Index. Br J Dermatol ; 168(5):1143-6.

- $\{10\}$ Sirois CM, Jin T, Miller AL, Bertheloot D, Nakamura $\mathrm{H}$ and
Horvath GL(2013) : RAGE is a nucleic acid receptor that promotes inflammatory responses to DNA .J Exp Med, 210 , pp. 2447-63.

- $\quad$ 11\} Cheong KA, Noh M, Kim CH and Lee AY (2014): S100B as a potential biomarker for the detection of cytotoxicity of melanocytes. Exp Dermatol; 23: 165-71.

- $\quad\{12\}$ Speeckaert R, Voet S, Hoste E and van Geel N (2017): S100B is a potential disease activity marker in non- segmental vitiligo. J Invest Dermatol ; 137: 1445-53 . 